\title{
THE LIVERPOOL MEDICAL SCHOOL IN MORECAMBE BAY: PROGRESS REPORT
}

\author{
Mike Flanagan, Undergraduate Sub-Dean \\ Morecambe Bay
}

This article is intended for all our readers but the action plan applies mostly to hospital-based activities. The next issue of the journal will concentrate on development in primary care.

The process of bringing Liverpool medical students to Morecambe Bay is, at this stage, a development project in the hands of quite a small number of people. This almost certainly means that you are one of those who wants to know what's happening and what to expect in the next few years. Things will happen at an increasing pace until our first group of year $\mathbf{4}$ students arrive.

First, some reminders of where we started:

- approval was given to expand the annual intake at Liverpool by 50 students, starting in September 2001

- Morecambe Bay, in the broadest sense of primary and secondary care, would receive these students for the year 4 curriculum starting in September 2004 and continuing thereafter

- the structure of the course is such that

a) students complete their 'final' exams at the end of this year

b) apply for and are appointed to their first PRHO jobs which, in turn,

c) has a direct effect on their whereabouts in year 5 (more about this later).

\section{THE CURRICULUM FRAMEWORK FOR US}

Be aware of what the students should already know. Three years of meeting in PBL groups will have given them their learning skills. They will have discussed and investigated over 40 scenarios. They are partway along the iterative process of study and will not be 'green' about your subject. In year 2 they study normality and in year $\mathbf{3}$ they learn the recognition of abnormality. Their presence in year $\mathbf{4}$ is to learn diagnosis of disease and patient management.

\section{Year 4}

- comprises three elements

1) three 12 -week rotations of clinical practice $=36$ weeks

2) final exams

3) a special study module (SSM)

$$
=2 \text { weeks }
$$

$=4$ weeks

42 weeks

The three clinical rotations are

1) surgery ( 8 weeks $)+$ palliative care (4 weeks)

2) medicine (8 weeks) + geriatrics (4 weeks)

3) obstetrics/gynaecology (4 weeks), paediatrics

(4 weeks) + psychiatry (4 weeks)

36 weeks

- the minimum standard for delivery is two days per week in hospital and one day in GP practice
- an intercalated degree may be done at the end of this year, subject to approval. All degrees require completion of a supervised research project.

Year 5

- is an intensive, apprentice-based clinical experience with half-day release to theoretical teaching. It is a rehearsal for the PRHO year.

- comprises five blocks of eight weeks each, in random order

block 1 shadowing the PRHO in one's intended job

block 2 accident and emergency care

block 3 community practice

block 4 student selective

block 5 student selective

8 weeks

8 weeks

8 weeks

8 weeks

8 weeks

40 weeks

Students selectives are called selectives in advanced medical practice or SAMPs. Students choose attachments which will allow them either to pursue a special interest or help them brush up in areas of weakness.

- has no formal exam but students must keep a portfolio of continuous assessment through each clinical attachment.

\section{WHAT THIS MEANS FOR US}

In year 4

- we have guaranteed numbers of students

- clinical rotations appear startlingly short (eight weeks for all of surgery or medicine!)

- each week has a minimum of two days and a maximum of four days in hospital, even less time than we are used to. Remember, up to $30 \%$ of the new Liverpool curriculum is delivered in primary care

- there is a core syllabus of cases to be learned, published by the medical school. (A syllabus is a list of facts, skills, attitudes etc which defines professional competence and proficiency.) In practice, this core syllabus amounts to the normal currency of clinical cases in any DGH or GP surgery

- we will be helping students to prepare for their final exams

- crucially, we will be attracting and appointing our future house officers.

In year 5

- student numbers are not guaranteed and may fluctuate depending on student selectives. Students doing their PRHO jobs elsewhere will not 'shadow' here. They will be in their intended hospital. Selectives (SAMPs) may go 
anywhere. Equally, we may recruit selectives from other locations if we develop attractive programmes.

- Students will require the same input (and, therefore, the same organisation and infrastructure) within your directorate as PRHOs. In effect, they will be doing something similar to the house officer 'locums' we ourselves did in our final year. This will have a bigger impact on service in some clinical areas than in others, eg A\&E. The planned distribution of educational money will take account of differing needs.

\section{THE STEERING GROUP}

This group comprises situation vacant Miss Anne Garden Dr Jean Quinn Ms Gillian Bridgett Mr Nigel Purcell Dr Ian Pickering

Dr Jim Gardener

Mr Ian Cumming

Dr Andy Luksza

Dr Mike Flanagan

Dr Bill Mitchell

Mr Peter Benning

Dr Trevor McMillan

Prof Jacqui Filkin

the dean of medicine
director of medical studies
director, community studies
administrative sub-dean
educationalist
administrator
MBHA/PCT
chief executive
medical director
undergraduate sub-dean
associate sub-dean
education manager
Lancaster University
S Martin's College

We meet at regular intervals and have made an assumption that equal numbers of year 4 students will progress to year 5 here. This being so, our projected presence of students at the outset would have been

\begin{tabular}{|l|c|c|c|}
\hline & Year 4 & Year 5 & origin of PRHOs \\
\hline $2004 / 5$ & 50 & 0 & from anywhere \\
\hline $2005 / 6$ & 50 & 50 & from anywhere \\
\hline $2006 / 7$ & 50 & 50 & $\begin{array}{c}\text { our own year 4 } \\
\text { cohort of 2004/5 }\end{array}$ \\
\hline
\end{tabular}

Three factors modified events quite rapidly:

1 Liverpool needed new GP practices to deliver the existing year 5 community module in 2000/2001. Ahead of time, five blocks of eight students (total 40) did their community module in practices local to Furness General Hospital (FGH). This was a resounding success which is being repeated this year plus a further 40 in the Lancaster/Kendal axis (total 80).

2 It was realised that the long wait for and abrupt arrival of 50 students in 2004/5 would be difficult. A pilot project of 24 students from year 4 was approved for $2003 / 4$. These students will pick their PRHO jobs for August 2005 at the end of their time with us.

3 Government approved a second increase in student numbers. A further 24 students from year 4 will arrive in 2006/7.

Combining these elements gives a new projected population as shown in Table 1.

Please think carefully about these numbers. It will help to give you a better perspective. Colleagues are often fearful about 'finding time to teach' when they are already

\begin{tabular}{|llll|l|}
\hline & Year 4 & Year 5 & \multicolumn{2}{c|}{ Community module } \\
\hline $2001 / 2$ & & & 80 & for 'other' \\
\hline $2002 / 3$ & & & 80 & teaching \\
\hline $2003 / 4$ & 24 & & 80 & hospitals \\
\hline $2004 / 5$ & 50 & 24 & $? 50$ & \\
\hline $2005 / 6$ & 50 & 50 & & \\
\hline $2006 / 7$ & 74 & 50 & & Morecambe \\
\hline $2007 / 8$ & 74 & 74 & & Bay \\
\hline
\end{tabular}

Table 1

overstretched. If you make an assumption that numbers are divided equally between Lancaster/Kendal and Barrow, then in year 2003/4 we will have 12 students at each site for 36 weeks. There will be three clinical rotations as described. At any given time, therefore, only four students will be doing a clinical attachment within your specialism in your hospital.

In 2004/5, these numbers will double for year 4 plus you will have a share of year 5 and so on. We have ample time to ascend the ladder to full numbers in 2007/8 (finding space is a bigger headache than supporting our job plans).

\section{Other activities of the steering group}

Enabling works are essential in any project. They are unglamorous, confusing at times, messy, frustrating and peppered with black holes which turn one's brain into a walnut. These are the precise reasons why the actual presence of 80 year 5 students throughout the bay this academic year is so welcome and invigorating. Regretfully, they have little presence in our hospitals but this may change. They are delightful: self-assured, relaxed, funny and very wellmotivated.

What are these enabling works?

1 Understanding each other

Developing key relationships between people in primary and secondary care, the universities of Liverpool and Lancaster, S Martin's college, the health authority/PCT, the NHS executive and others

\section{Understanding the curriculum}

In this context 'curriculum' refers to the aims of the course, the learning methods, assessment procedures and the organisation of the syllabus (remember, a syllabus describes what is to be taught or learned).

The curriculum directs - the educational environment

- how students and teachers should act and what they should learn/teach

- which in turn defines the training needs of teachers

- which then give an indication of support required and the impact on service delivery

The curriculum has had a powerful impact on strategic planning.

\section{Understanding the students}

Some things never change (learning to be a doctor is a parttime occupation. Make the rest up for yourself!). We know from talking to students at other sites and our own students at FGH last year that they ask for

- a well-organised programme and good facilities

- a friendly welcome in a place which expects their arrival

- a secure, safe environment in hospital and elsewhere 
- acceptable accommodation

- a good social life

Some things are different about Liverpool students on the new curriculum.

- Their learning methods are different to ours, which has a direct effect on us, their teachers. For example, an orthopaedic surgeon in clinic can no longer expect a student to name and identify, say, the bones of the carpus. Discussion about conditions of the wrist cannot assume any prior knowledge of anatomy. The teacher may need to set this knowledge as a learning objective. Unlike us, these students are learning anatomy, physiology and pharmacology on a 'need to know' basis in support of the clinical condition. This causes great frustration to certain teachers who have not grasped the radical change in educational method. There is, however, no going back. The GMC is explicit about the need to reduce the factual content and enhance patient-centred learning. Every medical school will follow, perhaps in varying degree, in due course.

- they are very self-directed (but still love a little spoonfeeding, as David Gorst observed)

- they are computer-dependent

- the sex ratio is $60: 40 \mathrm{~F}: \mathrm{M}$

- $30 \%$ are from other ethnic backgrounds

4 Finance

There is no guaranteed revenue in hospitals until 2004/5. Even the pilot year 4 in 2003/4 is not yet funded. Payments for the community module go straight to GPS.

- adequate financial systems do not exist and are being developed

- directorate managers are seen as key to business planning

\section{Educational facilities}

FGH has had some refurbishment including a clinical skills lab. More is planned. The seminar room will be divided into three, plus improved office and administration facilities. It already has excellent seminar facilities near wards and a truly multi-disciplinary education centre. A business case has been submitted to regional office for a two-phase development at RLI. Briefly, phase 1 will be built adjacent to the existing postgraduate medical centre which will continue to provide facilities during construction. This will then be demolished and phase 2 will replace the original centre. Educational space will treble. It will be available to all NHS staff, a long overdue multidisciplinary facility to match those at FGH and WGH. On-call rooms and a students' common room are planned on an upper floor. The whole will be linked to the Centenary building. Early indications for approval from the region are favourable.

All sites must recapture educational space which has been taken for administrative or secretarial use, especially near wards or in OPD. Funding must be identified. This recovery is not part of the reprovision of education centres but must be integral to each and every clinical development or refurbishment within directorates.

\section{Libraries}

Investment has occurred in libraries. All students now have individual identified access to all facilities at all times. Extra computers and word processors have been provided. Facilities at WGH are currently being expanded and a similar scheme is planned for FGH.
7 Other important factors

The first round of evaluations has occurred with regard to

- IT

- accommodation

- pastoral care

- transport.

Where we go next depends on some strategic decisions which will need input from the students themselves. Students in year 4 normally pay their own accommodation expenses which, since they will be here for the full academic year, means living here and not in Liverpool. If so, what do we do about sporting and recreational facilities, student health and welfare? Is it practical or desirable to bus them around the bay for any reason? We know that there is no capital to build accommodation (except on-call rooms) which, in any case, is now seen as unjustifiable throughout the NHS. There are plenty of options, however, and the steering group does not foresee major problems provided we have good input from the students.

\section{ACTION PLAN}

What's next? What should you do? Sufficient preliminary steps are in place for the next important phase of development. Leaving aside such matters as accommodation, transport, pastoral care, finance and managerial systems for the time being, concentrate first on the organisation and delivery of teaching. (Note: there will be a vital place for certain people to be involved in some of these issues notably pastoral care - but that comes later.)

\section{Step 1}

understand the curriculum

understand the syllabus

1 NHS staff in all disciplines are encouraged to become familiar with the new curriculum course handbook. Individuals and directorates at each site including Kendal will shortly be given:

the new curriculum MBChB course handbook the tutor guide for year 4 clinical attachments the core case syllabus

2 Visit the websites for undergraduate course material: www.liv.ac.uk/FacultyMedicine/home.html www.liv.ac.uk/FacultyMedicine/mbchb/ugcourse.html

3 Meetings will be arranged between specialities and faculty representatives from Liverpool in order to develop a greater understanding of the curriculum and what is required of us. Peter Benning will be contacting appropriate people in directorates to arrange dates. $\mathrm{He}$ must be present at such meetings along with either Bill Mitchell or me.

In addition, we should meet colleagues in other hospitals in the Liverpool scheme. We don't want to reinvent the wheel.

\section{Step 2}

Make an outline draft activity/teaching programme and submit it to the steering group for approval. This should be done by early 2002 .

\section{Step 3}

At the same time, and working with your directorate 
manager, quantify the impact of education on service and identify specific obstacles, difficulties and opportunities (eg teaching space, staff numbers).

\section{Step 4}

Where appropriate, prepare business plans to solve these problems. If this happens by next summer, there will be ample time to prepare for September 2003. Don't forget the PCT.

\section{Step 5}

Think about developing SSMs (for any year) and SAMPs for year 5 . Information and guidance notes will be provided. Try not to worry about things like accommodation. Leave that to the steering group. Focus on having students in your company. It is a valuable means of filling the gap between now and 2003/4.

\section{Step 6}

Avail of any other contact you enjoy. Volunteers are needed for

- admission interviews

- examinations

Expect a formal invitation before long.

\section{Reality check}

The association with Liverpool is not Eldorado. Staff expansion will not occur except by joint proposals with other sources of funding. On the other hand, there will be new money which will support education.

The directorate structure by itself will not serve all of the development needs. Smaller groups of enthusiasts will be formed to oversee certain things such as training the trainers, IT skills and so on. In part, this depends on other strategic decisions within the acute trust. Whatever happens, these fundamental principles apply, as agreed by our chief executive:

- after a topslice for its fixed costs, the trust will continue to identify education money in the annual budget which will support education. It will not go into the general pot, which gives such poor value in certain big city trusts we dare not name.

- there will be equitable distribution between all sites. Each hospital site will have unique opportunities to develop certain parts of the curriculum. These will be evaluated and supported for their individual worth. In other words, resources will not go pro-rata to directorates.

- a system of evaluation and priority allocation to pressure areas is inevitable

- funding will be withdrawn from directorates which fail to meet agreed commitments.

\section{Last words}

Let's remind ourselves what this is all for. We want students to come to Morecambe Bay to learn medicine on a course which happens to spend three years in Liverpool, not vice versa. We want the stimulus of these students to keep us on our toes, to make us better doctors, nurses - whatever - by the challenge they provide. We want the pleasure of seeing them mature under our tutelage. We want to exploit our skills, commitment and enviable location to recruit local youngsters and keep them in the profession. Most of all, when we ourselves become sick or old, we should expect to be cared for by doctors who are skilled, kind and compassionate. 